\title{
XXIV Encuentro del Grupo de Editores de las Revistas de las Sociedades de Pediatría del Cono Sur, Buenos Aires-Argentina 2019
}

\author{
XXIV Meeting of the Editors Group of the Journals of the Cono Sur Paediatric \\ Societies, Buenos Aires-Argentina 2019
}

\section{Luisa Schonhaut B. ${ }^{a}$}

aComité Editorial, Revista Chilena de Pediatría. Clínica Alemana, Facultad de Medicina, Universidad del Desarrollo

Los días 31 de octubre y 1 de noviembre se realizó el XXIV Encuentro de Editores de las Revistas pediátricas del Cono Sur en la ciudad de Buenos Aires. Los países participantes fueron Argentina, Brasil, Chile, Paraguay, Uruguay. Como es tradición, los editores presentaron las novedades editoriales de las revistas, se seleccionaron los 10 manuscritos destacados entre los publicados en las Revistas pediátricas del Cono Sur. Se discutieron temas de interés común, como la importancia de la continuidad del equipo editorial y la sustentabilidad de las revistas. Se propuso la incursión en las redes sociales como forma de mantener el liderazgo en temas científicos, y se replantearon los objetivos para los próximos encuentros.

A lo largo de los años las revistas han tenido importantes logros, destacando que todas están indexadas en la red SciELO (Scientific Electronic Library on Line), y 3 de ellas están además en Pubmed (Brasil, Argentina y Chile). Todas las revistas participantes en el encuentro migraron a plataformas digitales de gestión editorial, con distintos grados de experiencia; mientras que las de habla hispana optaron por el Open Journal System (OJS), el Jornal de Pediatria lo hace a través de Elsevier.

Las revistas participantes son los órganos oficiales de las sociedades científicas de pediatría de los respec- tivos países, siendo esta la fuente principal de financiamiento, apoyadas por los aportes que generan los avisos publicitarios. No obstante, en la medida que se ha regulado la participación de la industria farmacéutica $y$, que las revistas han pasado a formato electrónico, el aporte externo ha disminuido. Por otro lado, el mayor flujo de manuscritos, la profesionalización del trabajo editorial, traducción al idioma inglés y demás iniciativas tendientes a aumentar la visibilidad de las publicaciones, ha aumentado los costos de producción. Las revistas han implementado distintas estrategias tendientes a asegurar la sustentabilidad manteniendo la modalidad de acceso abierto. Archivos Argentinos de Pediatría y Jornal de Pediatria comenzaron a cobrar un arancel a los autores por la publicación, para contener los costos de diseño, impresión y distribución, siguiendo políticas de protección del medio ambiente, se ha disminuido la extensión y el tiraje de las publicaciones impresas. En Chile, se ha mantenido sólo un $10 \%$ de las publicaciones en papel para un grupo de socios que prefieren esta modalidad y para distribución en bibliotecas, mientras que Jornal de Pediatria ha optado por la publicación digital exclusiva y en idioma inglés, mientras que Archivos Argentinos de Pediatría ha limitado el número de páginas impresas.

Otra de las dificultades transversales es lograr revi- 
Tabla 1. Manuscritos seleccionados en el XXIV Encuentro de Editores de las Revistas pediátricas del Cono Sur

\section{Argentina}

1. Martins $\mathrm{E}$, et al. Contribución de la dieta a la exposición al plomo de niños de 1 a 7 años en La Plata, Buenos Aires. Arch Argent Pediatr 2018;116(1):14-20.

2. Alda $\mathrm{E}$, et al.Resultados del Programa Nacional de prevención de la Ceguera en la infancia por Retinopatía del Prematuro en Argentina (2004-2016). Arch Argent Pediatr 2018;116(6):386-93.

\section{Brasil}

1. Sadovsky AD, et al. Socioeconomic inequality in preterm birth in four Brazilian birth cohort studies.J Pediatr (Rio J). 2018;94(1):15-22

2. Caldas JP, et al.Effectiveness of a measure program to prevent admission hypothermia in very low-birth weight preterm infants.J Pediatr (Rio J). 2018;94(4):368-73.

\section{Chile}

1. Álvarez CA, et al. Estudio de adaptación y validación transcultural de una escala de satisfacción con la vida para adolescentes. Rev Chil Pediatr. 2018;89(1):51-8.

2. Velasco-Benítez CA, et al.Superposición de desórdenes gastrointestinales funcionales en escolares y adolescentes latinoamericanos. Rev Chil Pediatr. 2018;89(6):726-31.

\section{Paraguay}

1. Báez $L$, et al. Costo de los accidentes de moto en menores de 19 años atendidos en un hospital de referencia. Pediatr (Asunción). 2018;45(2):135-40.

2. Araya $S$, et al. Factores pronósticos de mortalidad en niños con bacteriemias adquiridas en la comunidad (BAC) hospitalizados en un centro de referencia del Paraguay. Pediatr (Asunción). 2018;45(1):17-24.

\section{Uruguay}

1. Beltramo P, et al. Mortalidad prenatal en el Centro Hospitalario Pereira Rossell, Montevideo. Análisis de 845 casos de autopsia entre 2005 y 2016. Arch Pediatr Urug. 2018; 89(1):5-14.

2. Fernández C, et al.Colonización nasofaríngea por serotipos de Streptococcus pneumoniae en niños uruguayos antes y después de la introducción de las vacunas antineumocóccicas conjugadas. Arch Pediatr Urug. 2018;89(4):235-41.

siones oportunas y completas. Brasil aumentó la participación de los editores en la preselección de los manuscritos que serán publicados; Argentina envió una convocatoria para invitar a los investigadores del país a participar como revisores y desarrolló un curso online gratuito; Uruguay incorporó en su equipo editores metodológicos y de estilo. Chile amplió el comité editorial el año 2018 y actualizó su equipo de asesores editoriales. Algunas revistas están enviando un certificado de agradecimiento a los revisores destacados, además de publicar los nombres de todos los revisores participantes, en el último número de cada revista.

Se seleccionaron los 10 trabajos más destacados entre los publicados en las revistas del Cono Sur el año 2018 (tabla 1). De Chile fueron reconocidos los manuscritos: "Estudio de Adaptación y validación transcultural de una escala de satisfacción con la vida para adolescentes" de los autores Álvarez C y colaboradores y "Superposición de desórdenes gastrointestinales funcionales en escolares y adolescentes latinoamericanos" de Velasco-Benítez AC y colaboradores.

Finalmente se discutieron los objetivos para los próximos encuentros, considerando los cambios ocurridos a nivel de las revistas a lo largo de las más de dos décadas en que se realizan las reuniones. Se propuso escribir manuscritos relacionados con aspectos de interés editorial que cuenten con la colaboración del grupo de editores, y puedan ser publicados simultáneamente en las revistas participantes.

Sin duda, la disparidad en las realidades culturales, sociales, editoriales y científicas de cada uno de los países participantes es el gran desafío y a su vez la riqueza de los encuentros de Editores de las Revistas pediátricas del Cono Sur, que año a año se han ido consolidando como un grupo afiatado compartiendo a través de las reuniones un proceso de continuo aprendizaje. 